\title{
Fuzzy Evaluation Algorithm for System Effectiveness of Wireless Sensor Networks
}

\author{
Cun-xiang Chen, Zun-wen He, Jian-guang Jia, Jing-ming Kuang, Zhong-yu Zhang \\ Research Institute of Communication Technology \\ Beijing Institute of Technology \\ Beijing, China \\ ccx7210@gmail.com
}

\begin{abstract}
Evaluation of System Effectiveness (SE) plays a significant role in network design, construction, optimization, etc. of Wireless Sensor Networks (WSNs). This paper develops a rational and comprehensive five-layer indicator model which incarnates SE or monomial efficiency of WSNs. Also, we propose a valid evaluation model HFCE with Analytic Hierarchy Process (AHP) and Fuzzy Comprehensive Evaluation (FCE), both of which combined together is suitable for hierarchical indicator model and multiattribute decision analysis of WSNs. The results obtained from simulation demonstrate practicability of indicator model and accuracy of evaluation model.
\end{abstract}

Keywords-evaluation model, indicator model, system effectiveness, wireless sensor networks

\section{INTRODUCTION}

Wireless Sensor Networks (WSNs) with heterogeneous sensing, wireless communication, and data processing are widely applied in various fields [1]-[3]. So it poses great challenges to System Effectiveness (SE) which leads direct impetus to its application. Methodical and efficient solution to $\mathrm{SE}$ is effectiveness evaluation through which it can play a leading role in system design by comprehensive analysis of key influencing factors and guide system optimization with identifying some problems during design, development, and operating stages.

The current research of SE for WSNs is mainly focused on monomial effectiveness evaluation, such as QoS, localization, network protocol performance, and energy consumption, etc. For QoS evaluation, there are some available models and mediums. Based on established QoS model and fuzzy logic, a relative holistic conclusion is achieved by studying the twoway mapping between network layer and application layer [4][5]. Still, in terms of various evaluation contents and targets, Rough Set theory is capable of condensing evaluation frame of WSNs which is composed of five parts [6]. As far as localization in WSNs, some experiments are carried out indoors or in rainforests to verify the assessment with localization techniques in [7] and [8]. With respect to the evaluation of MAC, some parameters matching the tested features are brought in to collect the packets and collision information [9]. Moreover, a classical mathematical modelMarkov is employed in node behavior of MAC protocols on

This research was supported by national major project of science and technology, China (Grant no. 2010ZX03006-002-03). estimation performance, and filtering model-Kalman is used to illustrate the approaches of multi-sensor [1]. With regard to the vital aspect system energy consumption, novel fuzzy metric logic is introduced to further acquire the superiority of different clustering schemes so as to prolong lifetime [10]-[12].

All hereinabove center on simplex approach to evaluate some part of WSNs performance, however, owing to some unique characteristics of WSNs, such as limited energy, non end-to-end network, redundant nodes and data, etc. traditional standard and method of effectiveness evaluation cannot meet requirements of WSNs. So it is essential to investigate indicator model and evaluation model. The former one is the basis of SE, and the latter one concerns core technology. It is hoped that this problem will be partly resolved with our proposed approach.

The remainder of this paper is organized as follows. Section II introduces indicator model with 5 levels and evaluation model with joint method HFCE. Section III presents evaluation method under classification of indicators. In Section IV, the simulation testing on evaluation and sensitivity of WSNs is conducted. Finally, our conclusions are presented in Section V.

\section{BuILding Related Models}

\section{A. Indicator Model for WSNs}

Indicator model abides by objectivity, decomposition, testability, integrity, and independence. Referring to the knowledge mentioned above, we put forward a topdown fivelayer indicator model which contains target layer, criterion layer, subcriterion layer, evaluation indicator layer, and scale parameter layer. Target layer the ultimate goal indicates System Effectiveness; criterion layer is composed of QoS, energy consumption, network management, and other crucial factor in view of system application; subcriterial layer represents significant task of each monomial efficiency; evaluation indicator layer designates primary aspects of each task; scale parameter layer reflects inherent characteristic of WSNs. This indicator model affords relatively rounded indicators, so the concrete indicator should be confirmed by its application. The main body frame of indicator model is expressed in Table I, II, III, IV, and V. 
TABLE I. INDICATOR MODEL FOR WSNS

\begin{tabular}{|c|c|}
\hline Target layer & Criterion layer \\
\hline \multirow{2}{*}{ E(System Effectiveness) } & $u_{1}$ QoS \\
\cline { 2 - 2 } & $u_{2}$ Energy management \\
\cline { 2 - 2 } & $u_{3}$ Network management \\
\cline { 2 - 2 } & $u_{4}$ Other factors \\
\hline
\end{tabular}

TABLE II. CRITERION LAYER-QOS INDICATOR MODEL

\begin{tabular}{|c|c|c|}
\hline $\begin{array}{l}\text { Criterion } \\
\text { layer }\end{array}$ & Subcriterion layer & Evaluation indicator layer \\
\hline \multirow{24}{*}{ QoS } & \multirow{6}{*}{$\mathrm{u}_{11}$ Application layer } & $\mathrm{u}_{111}$ Response time \\
\hline & & $\mathrm{u}_{112}$ Time synchronization \\
\hline & & $\mathrm{u}_{113}$ Node location \\
\hline & & $\mathrm{u}_{114}$ Data accuracy \\
\hline & & $\mathrm{u}_{115}$ Processing latency \\
\hline & & $\mathrm{u}_{116}$ System lifetime \\
\hline & \multirow{3}{*}{$\mathrm{u}_{12}$ Transmission layer } & $\mathrm{u}_{121}$ End-to-End latency \\
\hline & & $\mathrm{u}_{122}$ End-to-End bandwidth \\
\hline & & $\mathrm{u}_{123}$ End-to-End reliablity \\
\hline & \multirow{6}{*}{$\mathrm{u}_{13}$ Network layer } & $\mathrm{u}_{131}$ Expansibility \\
\hline & & $\mathrm{u}_{132}$ Path latency \\
\hline & & $\mathrm{u}_{133}$ Congestion probability \\
\hline & & $\mathrm{u}_{134}$ Energy efficacy \\
\hline & & $\mathrm{u}_{135}$ Routing maintenance \\
\hline & & $\mathrm{u}_{136}$ Routing robustness \\
\hline & \multirow{4}{*}{$\mathrm{u}_{14}$ MAC layer } & $\mathrm{u}_{141}$ Throughput \\
\hline & & $\mathrm{u}_{142}$ Accessing time \\
\hline & & $\mathrm{u}_{143}$ Energy efficacy \\
\hline & & $\mathrm{u}_{144}$ Transmission reliability \\
\hline & \multirow{5}{*}{$\mathrm{u}_{15}$ Physical layer } & $\mathrm{u}_{151}$ Channel speed \\
\hline & & $\mathrm{u}_{152} \mathrm{RF}$ power \\
\hline & & $\mathrm{u}_{153}$ Processing capability \\
\hline & & $\mathrm{u}_{154}$ Sensing accuracy \\
\hline & & $\begin{array}{ll}\mathrm{u}_{155} & \text { Sensing range } \\
\mathrm{u}_{156} & \text { Sensing power }\end{array}$ \\
\hline
\end{tabular}

TABLE III. CRITERION LAYER-ENERGY CONSUMPTION INDICATOR MODEL

\begin{tabular}{|c|c|}
\hline Criterion layer & Subcriterion layer \\
\hline \multirow{4}{*}{$\mathrm{u}_{2}$ Energy consumption } & $\mathrm{u}_{21}$ Application layer \\
\cline { 2 - 2 } & $\mathrm{u}_{22}$ Transmission layer \\
\cline { 2 - 2 } & $\mathrm{u}_{23}$ Network layer \\
\cline { 2 - 2 } & $\mathrm{u}_{24}$ MAC layer \\
\cline { 2 - 2 } & $\mathrm{u}_{25}$ Physical layer \\
\hline
\end{tabular}

TABLE IV. CRITERION LAYER-NETWORK MANAGEMENT INDICATOR MODEL

\begin{tabular}{|c|c|c|c|}
\hline $\begin{array}{c}\text { Criterion } \\
\text { layer }\end{array}$ & $\begin{array}{c}\text { Subcriterion } \\
\text { layer }\end{array}$ & \begin{tabular}{|c|} 
Evaluation \\
indicator layer
\end{tabular} & Scale parameter layer \\
\hline \multirow{22}{*}{$\begin{array}{c}u_{3} \\
\text { Network } \\
\text { Management }\end{array}$} & \multirow{5}{*}{$\begin{array}{l}u_{31} \\
\text { Information } \\
\text { acquisition } \\
\text { capability }\end{array}$} & $\begin{array}{l}u_{311} \text { Max early } \\
\text { warning range }\end{array}$ & \\
\hline & & \multirow{3}{*}{$\begin{array}{c}u_{312} \text { Target } \\
\text { identification }\end{array}$} & $u_{3121}$ False alarm rate \\
\hline & & & $\begin{array}{l}u_{3122} \text { Target discovery } \\
\text { probability }\end{array}$ \\
\hline & & & $\begin{array}{c}u_{3123} \text { Target identification } \\
\text { probability }\end{array}$ \\
\hline & & $\begin{array}{c}\mathrm{u}_{313} \text { Density of } \\
\text { information } \\
\text { acquisition }\end{array}$ & \\
\hline & \multirow{5}{*}{$\begin{array}{c}u_{32} \\
\text { Information } \\
\text { processing } \\
\text { capability }\end{array}$} & \multirow{2}{*}{$\begin{array}{c}u_{321} \text { Accuracy of } \\
\text { information } \\
\text { processing }\end{array}$} & $u_{3211}$ Data leakage rate \\
\hline & & & $u_{3212}$ Data presentation error \\
\hline & & \multirow{2}{*}{$\begin{array}{l}u_{322} \text { Synthesize } \\
\text { capacity }\end{array}$} & $\begin{array}{l}u_{3221} \text { Tran information } \\
\text { capability }\end{array}$ \\
\hline & & & $u_{3222}$ Data storage capacity \\
\hline & & $\begin{array}{l}u_{323} \text { Information } \\
\text { processing time }\end{array}$ & \\
\hline & \multirow{9}{*}{$\begin{array}{c}u_{33} \text { System } \\
\text { viability }\end{array}$} & \multirow{3}{*}{$\begin{array}{l}u_{331} \text { System } \\
\text { reliability }\end{array}$} & $\begin{array}{c}u_{3311} \text { Network communication } \\
\text { reliability }\end{array}$ \\
\hline & & & $\begin{array}{l}u_{3312} \text { Communication } \\
\text { equipment reliability }\end{array}$ \\
\hline & & & $\begin{array}{c}u_{3313} \text { Synchronous time source } \\
\text { reliability }\end{array}$ \\
\hline & & \multirow{2}{*}{$\begin{array}{c}u_{332} \text { System } \\
\text { serviceability }\end{array}$} & $u_{3321}$ Software fault-tolerance \\
\hline & & & $u_{3322}$ Mean time to repair \\
\hline & & \multirow{2}{*}{$\begin{array}{c}u_{333} \text { System } \\
\text { invulnerability }\end{array}$} & $u_{3331}$ Protective performance \\
\hline & & & $u_{3332}$ System recombination \\
\hline & & \multirow{2}{*}{$\begin{array}{c}u_{334} \text { Anti- } \\
\text { jamming ability }\end{array}$} & $\begin{array}{c}u_{3341} \text { Anti-electromagnetic } \\
\text { ability }\end{array}$ \\
\hline & & & $u_{3342}$ Anti-human disturbance \\
\hline & \multirow{2}{*}{$\begin{array}{c}u_{34} \text { System } \\
\text { control } \\
\text { capability }\end{array}$} & \multirow{2}{*}{$\begin{array}{l}u_{341} \text { Centralized } \\
\text { control ability }\end{array}$} & $u_{3411}$ Real time monitoring \\
\hline & & & $u_{3412}$ Topological control \\
\hline & $u_{35}$ Security & & \\
\hline
\end{tabular}

TABLE V. CRITERION LAYER-OTHER FACTORS INDICATOR MODEL

\begin{tabular}{|c|c|}
\hline Criterion layer & Subcriterion layer \\
\hline \multirow{4}{*}{$\mathrm{u}_{4}$ Other factors } & $\mathrm{u}_{41}$ Environment factor \\
\cline { 2 - 2 } & $\mathrm{u}_{42}$ People factor \\
\cline { 2 - 2 } & $\mathrm{u}_{43}$ Risk factor \\
\cline { 2 - 2 } & $\mathrm{u}_{44}$ Cost factor \\
\hline
\end{tabular}

\section{B. Evaluation Model}

To formally specify SE evaluation requirements in WSNs, a proper evaluation model is needed. In terms of system, evaluation model involves systemic design and adaptive strategy both of which rest with indicator model. So pretreatment origins in the classification of indicator. Furthermore, HFCE algorithm is a satisfactory solution to complete multiple criteria decision making (MCDM) and to eliminate fuzziness of indicators. The result can be in favor of system design or optimization. Figure 1 illustrates the integrated evaluation model. 


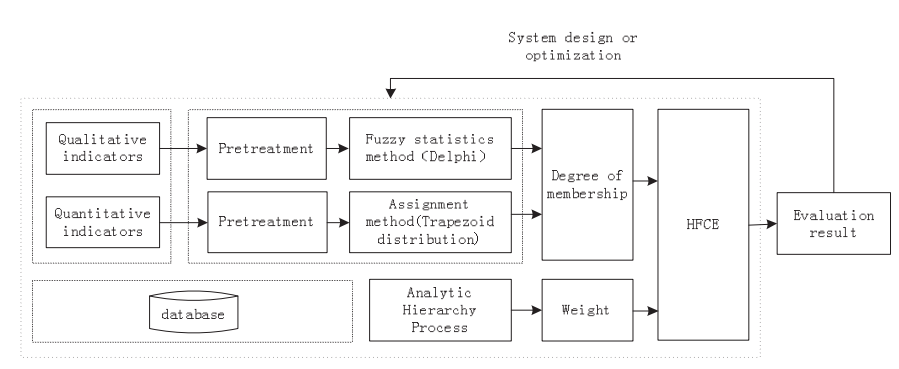

Figure 1. Evaluation model

\section{Evaluation Method}

\section{A. Pretreatment of Indicators}

Whether can be measured is the standard principle of indicator classification, hence we divide all indicators into two types: quantitative indicators and qualitative indicators. In order to eliminate incommensurability and contradictoriness, pretreatment through some mathematics method is significant for universalizing the criteria of measurement with different type of indicator.

\section{1) Pretreatment of Quantitative Indicators}

By the relationship between indicator value and SE, quantitative indicators can be partitioned into: positive influence indicator, negative influence indicator, and positive and negative influence indicator. If the line turns out to be positive slope, this indicator can be defined as positive influence indicator. On the contrary, it is known as negative influence indicator. Besides, positive and negative influence indicator is portrayed with a peak turning point in the growth of indicator value. At pretreatment stage, Utility Function is exploited to realize nondimensionalization and normalization of index attribute value. The ordinal transformation with these three types of indicator can be defined as

$$
\begin{aligned}
& v=f(x)=\left(x-x_{\min }\right) /\left(x_{\max }-x_{\min }\right), \quad x_{\min } \leq x \leq x_{\text {max }} \\
& v=f(x)=\left(x_{\max }-x\right) /\left(x_{\max }-x_{\min }\right), \quad x_{\min } \leq x \leq x_{\max } \\
& v=f(x)= \begin{cases}\left(x-x_{\min }\right) /\left(x_{o p t}-x_{\min }\right), & x_{\min } \leq x \leq x_{o p t} \\
\left(x_{\max }-x\right) /\left(x_{\max }-x_{o p t}\right), & x_{o p t} \leq x \leq x_{\text {max }}\end{cases}
\end{aligned}
$$

where $x$ obtained by simulation or actual measurement equals measurable indicator value, $x_{\max }$ and $x_{\min }$ respectively represent upper and lower bound of $x, x_{\text {opt }}$ is the optimal value in positive and negative influence indicator, and the calculation $v$ is the input variable of fuzzy evaluation method.

\section{2) Pretreatment of Qualitative Indicators}

Under the complexity of objective environment and fuzziness of subjective judgment, qualitative indicators are often decided by some experienced experts. At this period, we should confirm related specialist by all of qualitative indicators and apportion some evaluation indicators to them.

\section{B. Evaluation Method}

On the basis of hierarchic indicator model and fuzzy correlation of indicators, a joint evaluation method Analytic
Hierarchy Process (AHP) and Fuzzy Comprehensive Evaluation (FCE) is introduced. By simulating iterative operation with weight obtain from AHP and degree of membership offered by FCE, final evaluation value and further quantitative analysis can be got.

\section{1) Solution to Weight}

In accordance with hierarchic indicator model, the most appropriate solution to weight is AHP consisting of the following steps.

S1) Through paired comparison between two indicators with the same level, judgment matrix can be constructed as

$$
A=\left(a_{i j}\right)_{n \times n} .
$$

S2) Calculate maximum eigenvalue $\lambda_{\max }$ and maximum eigenvector vector $W$ of the judgment matrix.

S3) Check consistency ratio $C R$ as

$$
\begin{gathered}
C I=\left(\lambda_{\max }-n\right) /(n-1) \\
C R=C I / R I
\end{gathered}
$$

where $n$ is the order of the matrix; $R I$ and $C I$ are severally on behalf of random consistency index, consistency check index.

If $C R<0.1$, the consistency of judgment matrix fulfills the request and $W$ is the weight vector we want. Otherwise, the judgment matrix should be reconstructed. Accordingly, boundary value of maximum eigenvalue $\lambda_{\max }$ can be got as

$$
\lambda_{\max }=(C R * R I) *(n-1)+n
$$

The boundary of maximum eigenvalue is showed in Table VI.

TABLE VI. BOUNDARY VALUE OF MAXIMUM EIGENVALUE

\begin{tabular}{|c|c|c|c|c|c|c|c|c|c|}
\hline $\mathbf{n}$ & $\mathbf{1}$ & $\mathbf{2}$ & $\mathbf{3}$ & $\mathbf{4}$ & $\mathbf{5}$ & $\mathbf{6}$ & $\mathbf{7}$ & $\mathbf{8}$ & $\mathbf{9}$ \\
\hline$\lambda_{\max }$ & 1 & 1 & 3.116 & 4.288 & 5.448 & 6.62 & 7.792 & 8.987 & 10.16 \\
\hline 2) Solution to Single-stage Degree of Membership
\end{tabular}

Degree of membership denotes quantitative possibility of a factor assessed as some qualitative degree. The valid means for single-stage degree of membership depends on categories of indicators; trapezoidal fuzzy distribution is selected for quantitative indicators and typical Delphi is applied for qualitative indicators.

\section{a) Disposal of quantitative indicators}

Assignment method-trapezoidal fuzzy distribution is a universal and effective solution to different level fuzzy phenomenon. Trapezoidal fuzzy function is given by

$$
r(x)=\left\{\begin{array}{c}
0, \quad x \leq a \text { 或 } x \geq d \\
\frac{x-a}{b-a}, a<x<b \\
1, \quad b \leq x \leq c \\
\frac{d-x}{d-c}, c<x<d
\end{array}\right.
$$


where four parameters $a, b, c$, and $d$ refers to each value of vertexes in trapezoidal abscissa.

\section{b) Disposal of qualitative indicators}

Delphi can acquire quantitative results by experienced experts' judgments. Such is suitable for qualitative indicator which can only be measured by subjective opinions. Suppose $V$ be evaluation set and $r_{i j}$ indicating factor $i$ assessed as $V_{j}$ be degree of membership, there are $s$ from $m$ experts designating degree of membership of factor $i$ as $r_{i j}$. Then degree of membership of each qualitative indicator can be got as

$$
r_{i j}=s / m \text {. }
$$

The results in a) or b) by rules formulate fuzzy relation matrix $R$ and can be showed as

$$
R=\left[\begin{array}{c}
R \mid u_{1} \\
R \mid u_{2} \\
\vdots \\
R \mid u_{n}
\end{array}\right]=\left[\begin{array}{cccc}
r_{11} & r_{12} & \cdots & r_{1 m} \\
r_{21} & r_{22} & \cdots & r_{2 m} \\
\vdots & \vdots & \ddots & \vdots \\
r_{n 1} & r_{n 2} & \cdots & r_{n m}
\end{array}\right] .
$$

\section{3) Solution to Multi-stage Degree of Membership}

As the amount of level in indicator model is different, multi-stage method is required. From the lowest level, weight and degree of membership of each indicator can be deduced respectively through AHP and FCE presented in 1) and 2), through which degree of membership in upper level can be got by $M(\bullet,+)$ operator.

\section{4) Joint Method}

It ranges over HFCE joint method which contains both single-stage algorithm and multi-stage theory which is admissible depends upon the level of indicator. So from the bottom up iterative and crossover operation brings the degree of membership in the second level. Coupled with quantitative assessment grade we can easily catch concrete evaluation result which embodies SE and different single-stage efficacy under certain conditions.

\section{Simulation Analysis}

\section{A. Evaluation Set and Factor Set}

Evaluation set is composed of different assessment grades which are the natural language for subjective judgments of some indicator. So it can be set as $V=\{$ excellent, good, normal, $\mathrm{bad}$, and the corresponding evaluation fuzzy set is concretized as Table III.

TABLE VII. CONCRETIZED EVALUATION FuZZY SET

\begin{tabular}{|c|c|c|c|c|}
\hline \multirow{2}{*}{ evaluation level v } & \multicolumn{4}{|c|}{ evaluation fuzzy set } \\
\cline { 2 - 5 } & $\boldsymbol{a}$ & $\boldsymbol{b}$ & $\boldsymbol{c}$ & $\boldsymbol{d}$ \\
\hline excellent & 0.9 & 1 & 1 & 1 \\
\hline good & 0.7 & 0.8 & 0.9 & 1 \\
\hline normal & 0.5 & 0.6 & 0.7 & 0.8 \\
\hline bad & 0 & 0 & 0.5 & 0.6 \\
\hline
\end{tabular}

Factor set are equal to indicator model; target layer, criterion layer, subcriterion layer, evaluation indicator layer, and scale parameter layer correspond to the first, second, third, fourth, and fifth level, respectively.

\section{B. Measurement of Weight}

Take false alarm rate $\left(\mathrm{u}_{3121}\right)$, target discovery probability $\left(\mathrm{u}_{3122}\right)$, and target identification probability $\left(\mathrm{u}_{3123}\right)$ in scale parameter layer as example, all of which are factors of object identification quality. After thorough consideration, a judgment matrix is built as Table IV which meets the consistency requirements.

TABLE VIII. JUDGMENT MATRIX OF APPLICATION LEVEL IN QOS

\begin{tabular}{|c|c|c|c|}
\hline & $\mathbf{u}_{3121}$ & $\mathbf{u}_{3122}$ & $\mathbf{u}_{3123}$ \\
\hline $\mathrm{u}_{3121}$ & 1 & $1 / 5$ & $1 / 3$ \\
\hline $\mathrm{u}_{3122}$ & 5 & 1 & 3 \\
\hline $\mathrm{u}_{3123}$ & 3 & $1 / 3$ & 1 \\
\hline
\end{tabular}

Then the weight vector $W_{u_{312}}^{4}$ (superscript and subscript stand for the grade of target factor and concrete target factor) can be described as

$$
W_{u_{312}}^{4}=\left(w_{u_{3121}}, w_{u_{3122}}, w_{u_{3123}}\right)=(0.103298,0.650738,0.245964)
$$

According to the method revealed above, weight vectors in five-grade factor sets can be calculated with the same way, and can be expressed as

$$
\begin{aligned}
& W_{u_{312}}^{4}, W_{u_{321}}^{4}, W_{u_{322}}^{4}, W_{u_{331}}^{4}, W_{u_{332}}^{4}, W_{u_{333}}^{4}, W_{u_{334}}^{4}, W_{u_{341}}^{4} \\
& W_{u_{11}}^{3}, W_{u_{12}}^{3}, W_{u_{13}}^{3}, W_{u_{14}}^{3}, W_{u_{15}}^{3}, W_{u_{31}}^{3}, W_{u_{32}}^{3}, W_{u_{33}}^{3}, W_{u_{34}}^{3}, W_{u_{35}}^{3} \\
& W_{u_{1}}^{2}, W_{u_{2}}^{2}, W_{u_{3}}^{2}, W_{u_{4}}^{2}, W_{u}^{1} .
\end{aligned}
$$

\section{Measurement of Degree of Membership}

\section{1) Degree of Membership in the Fifth Level of Factor Set}

On account of connection between type of indicators and approaches to degree of membership, the coping mechanism with quantitative indicator-false alarm rate $\left(u_{3121}\right)$ abides by homologous solution. In accordance with practice, it is regarded as negative influence indicator which emerges crosscurrent phenomenon with system effectiveness, so its value is set 0.2 as minimum, 0.52 as current value, and 0.8 as maximum. Then the degree of membership of this indicator turns out to be a vector $r_{u_{3121}}=(0,0,0,1)$. After another two degree of membership of indicator $\mathrm{u}_{3122}$ and $\mathrm{u}_{3123}$ are gained, these vectors are organized as a matrix $R_{u_{312}}^{4}$ in order, where

$$
R_{u_{312}}^{4}=\left(\begin{array}{l}
r_{u_{3121}} \\
r_{u_{3122}} \\
r_{u_{3123}}
\end{array}\right)=\left(\begin{array}{llll}
0 & 0 & 0 & 1 \\
0 & 0 & 0.833000 & 0.16700 \\
0 & 0.200000 & 0.800000 & 0
\end{array}\right)
$$

Rest of degree of membership in this level can be acquired by the same way and expressed as 


$$
R_{u_{321}}^{4}, R_{u_{322}}^{4}, R_{u_{331}}^{4}, R_{u_{332}}^{4}, R_{u_{333}}^{4}, R_{u_{334}}^{4}, R_{u_{341}}^{4} .
$$

2) Degree of Membership in the Second, Third, and Fourth level of Factor Set

There are two kinds of factors in the second, third, and fourth level of factor set: one containing lower level indicators, and the other not. The former one exploits consequences of its lower level which become input variables through $M(\bullet,+)$ calculation; the latter one employs the same way as 1). Hence the ciphered consequences are combined into matrixes under the same level which prepares for the upper interactive computation. The detailed process is showed as

$$
\begin{aligned}
& R_{u_{1}}^{2}=\left[\begin{array}{l}
r_{u_{11}}=W_{u_{11}}^{3} \cdot R_{u_{11}}^{3} \\
r_{u_{12}}=W_{u_{12}}^{3} \cdot R_{u_{12}}^{3} \\
r_{u_{13}}=W_{u_{13}}^{3} \cdot R_{u_{13}}^{3} \\
r_{u_{14}}=W_{u_{14}}^{3} \cdot R_{u_{14}}^{3} \\
r_{u_{15}}=W_{u_{15}}^{3} \cdot R_{u_{15}}^{3} \\
r_{u_{16}}=W_{u_{16}}^{3} \cdot R_{u_{16}}^{3}
\end{array}\right] \\
& R_{u_{3}}^{2}=\left[\begin{array}{l}
r_{u_{31}}=W_{u_{31}}^{3} \cdot\left[\begin{array}{l}
r_{u_{311}} \\
r_{u_{312}}=W_{u_{312}}^{4} \cdot R_{u_{312}}^{4} \\
r_{u_{313}}
\end{array}\right] \\
r_{u_{32}}=W_{u_{32}}^{3} \cdot\left[\begin{array}{l}
r_{u_{321}}=W_{u_{321}}^{4} \cdot R_{u_{321}}^{4} \\
r_{u_{322}}=W_{u_{322}}^{4} \cdot R_{u_{322}}^{4} \\
r_{u_{323}}
\end{array}\right] \\
r=W^{3} \cdot\left[\begin{array}{l}
r_{u_{331}}=W_{u_{331}}^{4} \cdot R_{u_{331}}^{4} \\
r_{u_{332}}=W_{u_{332}}^{4} \cdot R_{u_{332}}^{4}
\end{array}\right]
\end{array}\right] \quad R_{u_{4}}^{2}=\left[\begin{array}{l}
r_{u_{41}} \\
r_{u_{42}} \\
r_{u_{43}} \\
r_{u_{44}}
\end{array}\right] \\
& \begin{array}{c}
r_{u_{33}}=W_{u_{33}}^{3} \cdot\left[\begin{array}{l}
u_{332}=W_{332} \\
r_{u_{333}}=W_{u_{333}}^{4} \cdot R_{u_{333}}^{4} \\
r_{u_{334}}=W_{u_{334}}^{4} \cdot R_{u_{334}}^{4}
\end{array}\right] \\
r_{u_{34}}=W_{u_{34}}^{3} \cdot\left[\begin{array}{l}
r_{u_{341}}=W_{u_{341}}^{4} \cdot R_{u_{341}}^{4} \\
r_{u_{35}}=W_{u_{35}}^{3} \cdot R_{u_{35}}^{3}
\end{array}\right]
\end{array} \\
& R_{u_{2}}^{2}=\left[\begin{array}{l}
r_{u_{21}} \\
r_{u_{22}} \\
r_{u_{23}}
\end{array}\right] \\
& R_{u}^{1}=\left(\left(r_{u_{1}}=W_{u_{1}}^{2} \cdot R_{u_{1}}^{2}\right)^{T},\left(r_{u_{2}}=W_{u_{2}}^{2} \cdot R_{u_{2}}^{2}\right)^{T},\left(r_{u_{3}}=W_{u_{3}}^{2} \cdot R_{u_{3}}^{2}\right)^{T},\left(r_{u_{4}}=W_{u_{4}}^{2} \cdot R_{u_{4}}^{2}\right)^{T}\right)^{T}
\end{aligned}
$$

\section{3) Evaluation result}

Based upon the evaluation fuzzy set defined at the beginning, we can acquire its mapped value which is revealed as $\mathrm{V}=\{0.9,0.8,0.7,0.6\}$. The evaluation results in the first and second level which embody the whole system effectiveness or different single-stage efficacy under specific design scheme are respectively named as $F, F_{u_{1}}, F_{u_{2}}, F_{u_{3}}, F_{u_{4}}$, where

$$
\begin{aligned}
& F=V \cdot\left(W_{u}^{1} \cdot R_{u}^{1}\right)^{T} \cdot 100 \\
& F_{u_{1}}=V \cdot\left(R_{u_{1}}^{2}\right)^{T}, F_{u_{2}}=V \cdot\left(R_{u_{2}}^{2}\right)^{T} \cdot 100 \\
& F_{u_{3}}=V \cdot\left(R_{u_{3}}^{2}\right)^{T}, F_{u_{4}}=V \cdot\left(R_{u_{4}}^{2}\right)^{T} \cdot 100 .
\end{aligned}
$$

The qualitative result can be got as Table IX.

TABLE IX. Qualitative RESUlt

\begin{tabular}{|c|c|c|c|c|}
\hline result (F) & $\mathbf{1 0 0} \leq \mathbf{F} \leq \mathbf{8 5}$ & $\mathbf{8 5}<\mathbf{F} \leq \mathbf{7 5}$ & $\mathbf{7 5}<\mathbf{F} \leq \mathbf{6 5}$ & $\mathbf{F}<\mathbf{6 5}$ \\
\hline qualitative result & excellent & good & normal & bad \\
\hline
\end{tabular}

\section{Indicator Sensitivity Analysis}

It is assumed that indicator is independent so as to get rid of the interaction among indicators. Indicator sensitivity involves the influence degree of SE caused by some indicator, and under given conditions can be derived as

$$
\phi_{E}=\frac{\Delta E}{\Delta B}
$$

where $\Delta E$ is the change value of $\mathrm{SE}$ and $\Delta B$ is equivalent change value of degree of membership.

Take system effectiveness under certain circumstance as example, the relationship between system effectiveness and degree of membership can be showed as Figure 2, 3, 4, and 5.

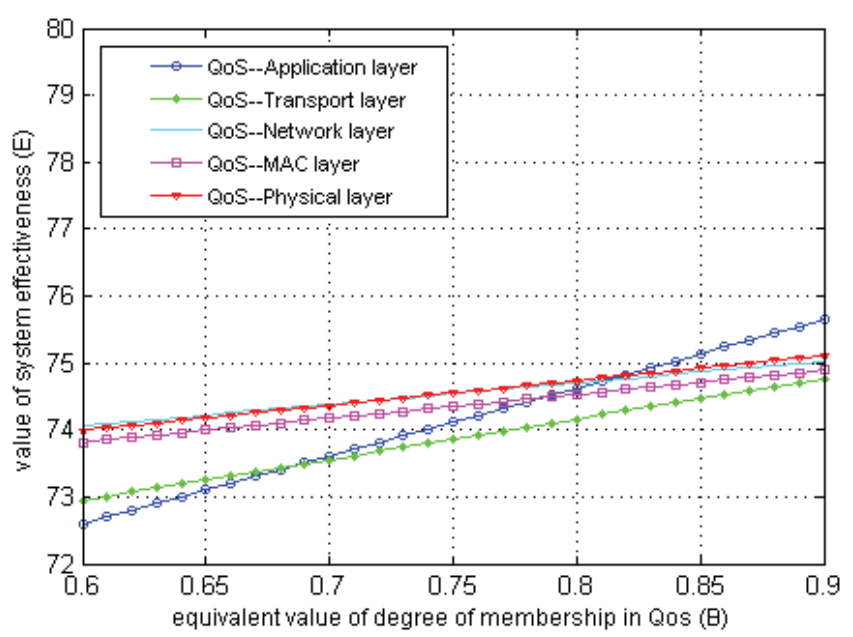

Figure 2. Relationship between SE and degree of membership in QoS

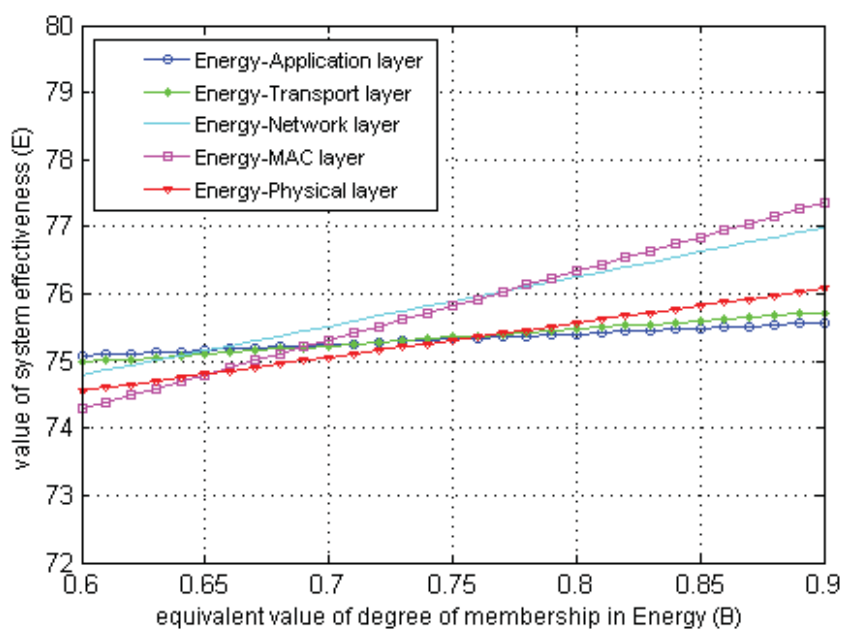

Figure 3. Relationship between SE and degree of membership in energy 


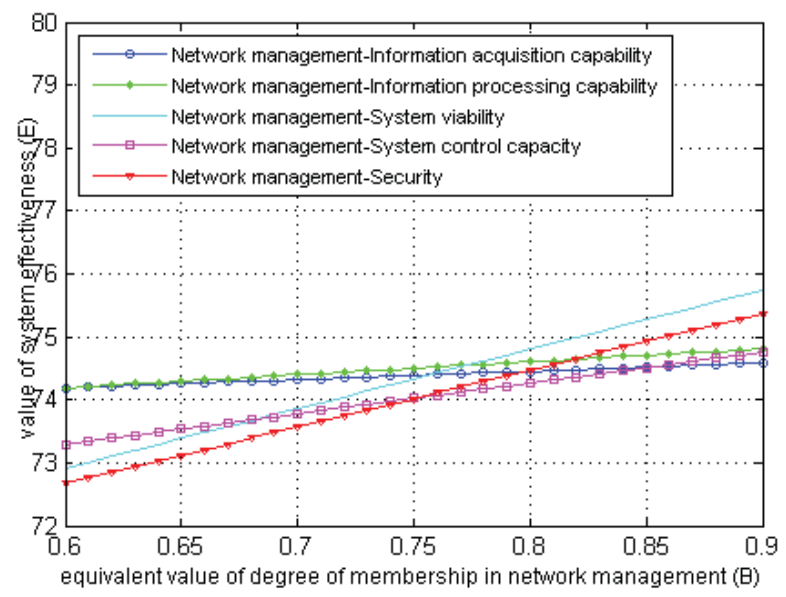

Figure 4. Relationship between SE and degree of membership in network management

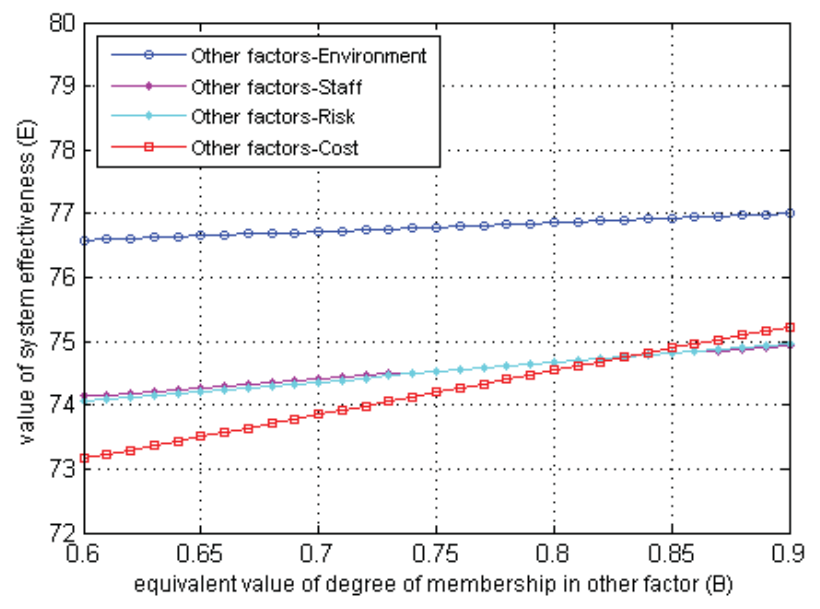

Figure 5. Relationship between SE and degree of membership in other factor

Indicator sensitivity can be got as (11) and illustrated as Figure 6. From the figure, slopes of application layer in QoS and MAC layer in Energy are bigger than any other layer, so they are more sensitive than others in this case. In practice, we should promote its performance as much as possible under the same conditions.

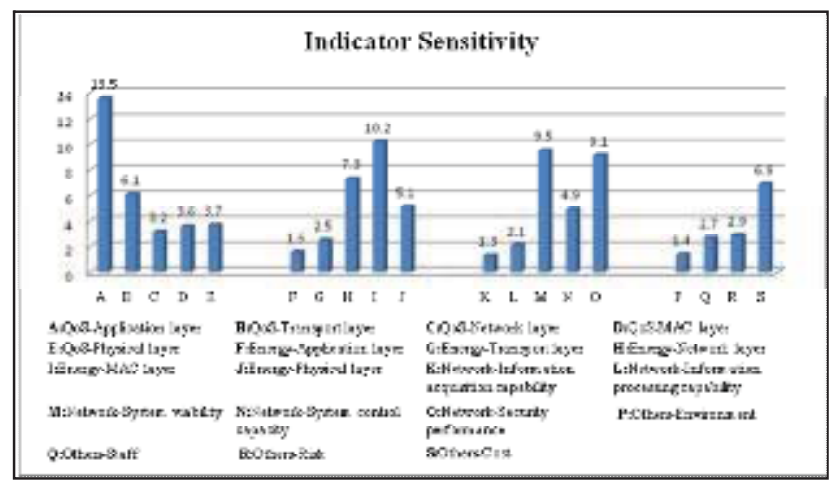

Figure 6. Indicator sensitivity

\section{CONCLUSION}

From the perspective of application, this paper mainly studies indicator model and evaluation method for WSNs. So we propose a universal hierarchy model which contains not only subjective factors but also objective factors, and HFCE theory with some improvement, such as indicator classification, pretreatment, etc. Simulation manifests these models combined together can directly reflect SE and some individual efficacy, and furthermore, from its result and sensitivity analysis it can render assistance to system design, development, and optimization.

\section{PREFERENCE}

[1] Bonnie Zhu, Bruno Sinopoli, Kammeshwar Poolla, and Shankar Sastry, "Estimation over Wireless Sensor Networks," in Proc. American Control Conference. New York, USA, 2007, pp. 2732-2737.

[2] Akyildiz I.F, Su W, Sankarasubramaniam Y, Cayirci E. Wireless sensor network: a survey[J]. Computer Networks, 2002, 38(4): 393-422.

[3] Zhu Ni, Yang Zhen. A Holistic QoS Framework for Wireless Sensor Networks [J].Communications Technology, 2006(9): 65-69.

[4] Deng Qiang, Xie Dong-liang, and Chen Shan-zhi, “A fuzzy logic based QoS evaluation model for Wireless Sensor Network, " in proc. 5th Wireless Communications, Networking and Mobile Computing, Beijing, China, 2009,pp.1-4.

[5] Wang xiaokai, Du WenZhuo, and Zheng Dongmei, "A class of the Wireless Sensor Networks QoS description and evaluation," in proc. 3th International Conference on Measuring Technology and Mechatronics Automation, Shanghai, China, 2011, pp. 16-19.

[6] Lun Zhang, Yan Lu, and Lan Chen, "Fuzzy Evaluation for Wireless Sensor Networks Based on Rough Set Theory," in proc. 27th Performance, Computing and Communications Conf., Austin, Texas, Dec.2008, pp.406 - 411 .

[7] Jhy-Ching Juang, Ta-Keng Weng, Pham Viet Cuong, Chang-Yi Hsu, Yihsueh Lee, and Sin-Hua Su, "Experimental Assessment of Wireless Sensor Network Localization Techniques," in proc. 10th Intl. Conf. on Control, Automation, Robotics and Vision, Hanoi, Vietnam, 2008, pp.335-340.

[8] Carlos M. S. Figueiredo, Eduardo F. Nakamura, Afonso D. Ribas, Thales R. B. de Souza, Raimundo S. Barreto, "Assessing the Communication Performance of Wireless Sensor Networks in Rainforests," in proc. 2009 2nd IFIP Wireless Days (WD), Pairs, France, 2009,pp.1-6.

[9] Agustin Barberis, Leonardo Barboni, and Maurizio Valle, “Assessment of the MAC Layer Behavior of Wireless Sensor Networks Simulators Using Experimental Testbeds," in proc. 2nd International Workshop on Advances in Sensors and Interface, 2007,pp.1-6.

[10] Peyman Neamatollahi, Hoda Taheri, Ehsan Toreini, Mahmoud Naghibzadeh, "A Novel Fuzzy Metric to Evaluate Clusters for Prolonging Lifetime in Wireless Sensor Networks," in proc. 2011 International Symposium on Artificial Intelligence and Signal Processing, 2011,pp.118-123.

[11] Mario Collotta, Giovanni Pau, Valerio M. Salerno, and Gianfranco Scata, "A fuzzy based algorithm to Manage Power Consumption in Industrial Wireless Sensor Networks," in proc. 9th IEEE International Conference on Industrial Informatics, 2011,pp.151-156.

[12] Ting Jiang, Pengjie Wu, Bin Shen, and Kyungsup Kwak, A Novel Fuzzy Algorithm for Power Control of Wireless Sensor Nodes. in proc. 9th International Symposium on Communications and Information Technology .2009,pp.64-68. 